\title{
Concepts, History, Principles, and Application of Germplasm Cryopreservation Technology ${ }^{1}$
}

\author{
Huiping Yang and Terrence R. Tiersch ${ }^{2}$
}

\section{Abstract}

Germplasm are living genetic resources that can serve as bearers of heredity, and include germ cells and their precursors, plant seeds and pollen, animal sperm, oocytes, embryos, and larvae. Cryopreservation refers to the preservation of biological materials at extremely low temperatures, sometimes using solid carbon dioxide at $-80^{\circ} \mathrm{C}$ or more commonly liquid nitrogen at $-196^{\circ} \mathrm{C}$ for freezing and cryogenic storage in perpetuity. Germplasm cryopreservation is an important technology applied for medical treatment, maintenance of biological diversity, preservation of valuable genetic resources, assistance of breeding programs, and conservation of imperiled species. This Extension publication is intended to introduce the basic concepts, history, principles, and applications of germplasm cryopreservation.

\section{What is cryopreservation?}

Cryopreservation is a technology for preservation of biological materials at extreme low temperatures, sometimes in solid carbon dioxide (dry ice) at $-80^{\circ} \mathrm{C}\left(-112^{\circ} \mathrm{F}\right)$ or typically in liquid nitrogen at $-196^{\circ} \mathrm{C}\left(-321^{\circ} \mathrm{F}\right)$. Theoretically, at cryogenic temperatures (lower than $-100^{\circ} \mathrm{C}$ ) biological materials cease their activities and metabolism (Pictet 1893, cited from Davenport 1897) and are capable of being revived with minimal changes after thawing to normal physiological temperatures. In fact, the reduction of body temperatures below $0^{\circ} \mathrm{C}$ ("cryo-hibernation") occurs in some amphibian species in nature. These species have developed protective mechanisms to survive extreme winters. For example, wood frogs (Rana sylvatica) can increase the concentrations of glucose and urea in their body fluids (Costanzo et al. 1991; Dueck 2018) to ward off ice formation. Cryopreservation technology is considered to be a tool for preservation of biological materials in perpetuity and has been applied in many fields. To date, biological materials used for cryopreservation study include organelles (structures within cells), gametes (sperm or eggs), single cells (blood cells, research cell lines), tissues, extracellular matrix, organs, bacteria, fungi, and plants.

The challenge of cryopreservation technology is to assure minimal damage to biological cells during cooling to cryogenic temperatures and thawing, which are major research topics for development of cryopreservation technology (Fuller et al. 2004). This research field is relatively new and involves multiple disciplines, including cell biology (e.g., size, structure, membrane, and enzymatic metabolism), chemistry (e.g., the action of cryoprotectants to protect cells), physics (thermodynamics during cooling and thawing processes), and computer modeling (e.g., to evaluate theoretical mechanisms related to temperature or ice formation). Due to the involvement of multiple disciplines, terminology is not standardized and can lead

1. This document is FA223, one of a series of the School of Forest Resources and Conservation, Program in Fisheries and Aquatic Sciences, UF/IFAS Extension. Original publication date April 2020. Visit the EDIS website at https://edis.ifas.ufl.edu for the currently supported version of this publication.

2. Huiping Yang, assistant professor, School of Forest Resources and Conservation, Program in Fisheries and Aquatic Sciences; and Terrence R. Tiersch, Aquatic Germplasm and Genetic Resources Center, School of Renewable Natural Resources, Louisiana State University Agricultural Center; UF/IFAS Extension, Gainesville, FL 32611.

The Institute of Food and Agricultural Sciences (IFAS) is an Equal Opportunity Institution authorized to provide research, educational information and other services

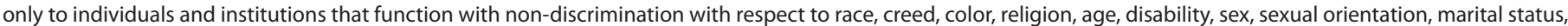

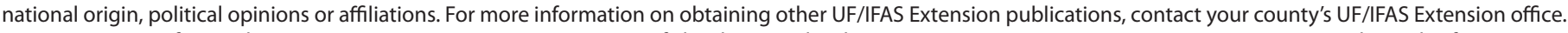
U.S. Department of Agriculture, UF/IFAS Extension Service, University of Florida, IFAS, Florida A \& M University Cooperative Extension Program, and Boards of County Commissioners Cooperating. Nick T. Place, dean for UF/IFAS Extension. 
to confusion or inhibit comparison of results or findings. Therefore, some definitions are provided below:

Cryopreservation: The process of preservation or conservation of biological materials at cryogenic temperatures (usually lower than $-180^{\circ} \mathrm{C}$ ). Cryopreservation of genetic materials of germ cells, such as seed, sperm, or eggs, is called Germplasm Cryopreservation. The cryopreservation of biological materials at an extremely high cooling speed without ice crystal formation is also called vitrification.

Cryobiology: Study of the effects of low temperatures on organisms (often for the purpose of achieving cryopreservation).

Cryogenics: A discipline within physics. The study of the production and behavior of materials at cryogenic temperatures.

Cryonics: This addresses the frozen storage of human corpses or heads with the speculative intention for future reanimation. This is usually considered to be outside of the realm of serious scientific research (website https://www. cryonics.org/).

Cryosurgery: A form of surgical technique applying cryogenic temperatures to destroy malignant tissues or cells.

Cryotherapy: The local or general use of low temperatures in medical therapy. The scientific basis concerning efficacy of these approaches, especially whole-body cryotherapy in cold chambers, has not received long-term or significant scrutiny.

Cryoelectronics: The study of electronic phenomena at cryogenic temperatures, such as superconductivity (useful for aerospace and telecommunication technologies). The practical application of superconductivity is called Cryotronics.

\section{A Short History of Germplasm Cryopreservation Technology}

The discovery of the cryoprotective effect of glycerol for sperm cryopreservation after World War II is widely recognized as the first report of germplasm cryopreservation (Polge et al. 1949). In this report, glycerol was found, by chance, to have protective capability during freezing. Fowl semen (spermatozoa within seminal fluids) were cooled to $-79^{\circ} \mathrm{C}$ after mixing with $20 \%$ glycerol in Ringer buffer (a pH-balanced solution to suspend cells) and resumed motility after thawing (not noticeably different from fresh sperm). However, glycerol performed differently in protection of spermatozoa from other species (Polge et al. 1949). For human spermatozoa, glycerol at 5\% was reported to increase the survival after thawing, while for rabbit spermatozoa, glycerol was found to be highly toxic above $5 \%$. This report laid the foundation for development of applied cryopreservation technology (see a comprehensive review in Pegg 2002).

Before this landmark study (Polge et al. 1949), there were many pioneering reports on cryopreservation technology worthy of consideration. Based on statements in one publication (Sherman 1973), Spallanzani in 1776 was perhaps the first to report observations on the effects of freezing temperatures on human spermatozoa (storage on snow for $30 \mathrm{~min}$ ). In 1866, Montegazza was the first to suggest banks for frozen human semen. In 1897 (Davenport 1897), a summary table based on research performed between 1840-1869 was provided stating that spermatozoa from amphibians (frogs) and mammals (humans) could tolerate temperatures of -4 to $-17^{\circ} \mathrm{C}$ and resume their motility after thawing. Later, artificial insemination was developed and has been advanced since 1899 (see a complete review about artificial insemination in Foote 2002). Thus, storage of spermatozoa, together with artificial insemination techniques, were needed to enable use of cryopreservation, especially for the dairy cattle industry (Walters et al. 2009). Cryopreservation investigations continued and typically focused on spermatozoa. Some important reports include:

1.In 1930, the effects of low temperature were studied on rabbit spermatozoa fertility (Hammond 1930). During storage at $0^{\circ} \mathrm{C}$, rabbit sperm lost fertility from $59 \%$ to $11 \%$ in $6 \mathrm{hr}$, and decreased to $0 \%$ within $16 \mathrm{hr}$.

2. In $1938-1939$, human spermatozoa were frozen to $-79^{\circ} \mathrm{C}$, $-196^{\circ} \mathrm{C}$, and $-269.5^{\circ} \mathrm{C}$ for the first time in glass tubes (Jahnel 1938). Spermatozoa could be revived after frozen storage for 40 days at $-79^{\circ} \mathrm{C}, 52 \mathrm{hr}$ at $-196^{\circ} \mathrm{C}$, and $3 \mathrm{hr}$ at $-269^{\circ} \mathrm{C}$. However, a follow-up study in 1939 showed that only a low percentage of human spermatozoa cooled in glass capillary tubes $(0.2-\mathrm{mm}$ diameter $)$ to $-79^{\circ} \mathrm{C}$, $-196^{\circ} \mathrm{C}$, and $-269^{\circ} \mathrm{C}$ could be revived by thawing after 70 days of storage at $-79^{\circ} \mathrm{C}$ (Shettles 1939).

3. In 1938, frog spermatozoa were frozen by immersion in liquid air after being partially dehydrated in a sucrose solution and spread in a thin film on a mica slip. These cells showed motility after rapid thawing by plunging into medium warmed to $20^{\circ} \mathrm{C}$ (Luyet and Hodapp 1938). 
4. In 1941-1942, chicken spermatozoa were cryopreserved to $-79^{\circ} \mathrm{C}$, and survival was observed after thawing (Shaffner et al. 1941). One year later, research indicated that spermatozoa frozen to $-76^{\circ} \mathrm{C}$ after having been dehydrated by addition of levulose showed $30 \%$ motility after a 52 -day storage at $-76^{\circ} \mathrm{C}$, but these thawed sperm did not produce offspring. The first-ever record of offspring production from frozen sperm was a single live chick produced from sperm frozen to $-6^{\circ} \mathrm{C}$ (Shaffner 1942).

\section{In 1942, human spermatozoa were frozen in liquid} nitrogen with an elaborate series of devices to facilitate instantaneous freezing. However, the revival of these sperm was poor (Hoagland and Pincus 1942).

6. In 1945, further studies were performed to freeze human spermatozoa by cooling ethyl alcohol with solid $\mathrm{CO}_{2}$ (Parkes 1945) rather than instantaneous freezing in liquid nitrogen. After thawing, "abundant spermatozoa" frozen in 0.5-mm- or 1-mm-diameter capillary tubes were revived, but no spermatozoa survived in $0.15-\mathrm{mm}$ diameter tubes. This was the first documentation of the difference in cell survival based on packaging containers. Additionally, freezing of samples to $-79^{\circ} \mathrm{C}$ or $-196^{\circ} \mathrm{C}$ did not reveal differences between capillary tubes with 1-mm-diameter or 5-mL pyrex ampoules.

Before 1949, there were reports in languages other than English on sperm cryopreservation. One is a report in Russian (Morozov 1940) describing studies on storage of bull sperm after dehydration and cooling to $-11^{\circ} \mathrm{C}$, and another one is in French titled "Glycérine et résistance du sperme aux basses temperatures" in 1946 (Rostand 1946) ("glycerin and sperm resistance at low temperatures").

As stated above, the finding that glycerol could serve as a sperm cryoprotectant opened a new pathway for development of cryopreservation technology. Since then, sperm cryopreservation has been investigated in many hundreds of different species, and significant achievements have been accomplished. For example, sperm cryopreservation in humans has become an effective tool for treatment of infertility, and sperm banking of cattle has developed into a multi-billion-dollar international industry for genetic improvement. Due to the large number of publications (Tiersch 2011a), we present examples of milestone events in different animal groups (Table 1). Readers who wish to learn more about the history and current status of cryopreservation technology can refer to the publications in Table 1 and correlated review publications.

\section{Principles of Cryopreservation Technology}

Before the discovery of glycerol as a cryoprotectant, all studies on germplasm cryopreservation were based on empirical observations of cellular and tissue behavior. These empirical studies formed the basis for subsequent development of fundamental theories within cryobiology about freezing success or failure. The discovery of cryoprotectants (e.g., glycerol, propylene glycol, and methanol) opened the doors for further development of germplasm cryopreservation technology through elucidating the function of cryoprotectants.

Generally, the materials being cooled are composed of biological cells, intracellular (within the cell) buffers, and cryoprotectants dissolved in extracellular (outside the cell) buffer. The core questions of cryopreservation technology are to quantify the biological, chemical, and biophysical changes during the processes of cooling and warming (thawing). Specifically, these studies include the exchange of water, cryoprotectant, and ions across the cell membrane (a semi-permeable membrane that allows only certain substances to pass through while keeping others in or out), cell size and structure changes, intercellular or extracellular changes with cryoprotectant addition or removal, extracellular or intracellular ice formation and heat transfer, and effects of cooling and warming rates. With experimental studies of a wide range of single cells, such as sperm, and blood cells including erythrocytes, lymphocytes, and hemopoietic cells, significant findings were made to uncover mechanisms responsible for cell injury during cryopreservation (Pegg 2002).

\section{Two Major Findings}

1. Cryoprotectants can influence the dehydration effects that damage cells. The increased concentration of intracellular or extracellular electrolytes (due to the removal of liquid water by transformation into ice during cooling) was shown to be a factor that could damage cells (Lovelock 1953a). Glycerol could function by preventing excessive increases in salt concentration during cooling (Lovelock 1953b), and it was suggested that permeable cryoprotectants could protect cells during cooling (Lovelock 1954).

2. Cryoprotectants can influence the formation of ice crystals that damage cells. First, it was suggested that glycerol modified the shape of ice crystals in a way that could protect cryopreserved cells (Smith et al. 1951). Further evaluation indicated that extracellular ice could 
form first depending on cell membrane permeability and cooling rate, and it was the formation of intracellular ice crystals that was most damaging to cells. This fundamental phenomenon was elucidated and analyzed with quantitative mathematical models (Mazur 1963, 1965, 1970).

Based on these two findings, a two-factor hypothesis was proposed for cell injury during cooling and warming (Mazur et al. 1972), and was illustrated well in a follow-up report with different types of cells (Leibo 1976). To date, this hypothesis has been recognized as the basis for our understanding of the dynamics of cryobiology. The hypothesis is proposed below.

1. At slow cooling rates, intracellular water will have sufficient time to leave the cells after ice formation in the extracellular medium, thus the solute concentration in cells will increase and could be detrimental (the "solute effect").

2. At fast cooling rates, intracellular water will not have sufficient time to leave the cells, and intracellular ice crystals will form and be detrimental ("intracellular ice formation").

3. At optimized cooling rates, the two effects stated above can be mediated, and the detriments to cells will be minimized for higher post-thaw cell survival.

4. At super-fast cooling rates, ice formation will result in a glass-like transformation (called "vitrification"), rather than crystallization, and the detrimental effects of ice crystals will be reduced.

In addition to these factors (solute effect and intracellular ice formation) leading to cell injury in the hypothesis, other potential factors that could damage cells during cooling or warming include the toxicity of cryoprotectants, dramatic osmotic changes, cell structure changes associated with temperature changes, cryoprotectant addition and removal (Pegg 2002), and warming rate.

\section{Procedure of Germplasm Cryopreservation}

We do not intend to provide detailed protocols of germplasm cryopreservation in this publication. Instead, a generalized procedure is introduced to illustrate the main points of the process. The steps of this procedure include (Tiersch 2011b):

\section{Sample collection and quality control}

Collection of germplasm samples (sperm, eggs, or larvae) would need to be performed by different methods based on the reproductive characteristics of target animals. For example, sperm from most fishes are adapted to external fertilization and are usually active for only a few minutes after release into the environmental water (freshwater or seawater), and thus sperm needs to be collected in buffered solutions (often referred to as "extender solutions") to prevent contact with fresh water or seawater (which activate sperm motility). After collection, fresh samples are usually analyzed with a series of assays, such as sperm motility and cell concentration, to evaluate sample quality. Only samples that meet specific quality criteria would be processed (Torres et al. 2017).

\section{Addition of cryoprotectants and equilibration}

The use of cryoprotectant molecules is almost universal for germplasm cryopreservation technology. For different cell types and animal species, effective cryoprotectant types and concentrations need to be determined through systematic experimentation based on toxicity, molecular weight, and permeability. Generally, cryoprotectants for germplasm cryopreservation include glycerol, propylene glycol, ethylene glycol, dimethyl sulfoxide (DMSO), methanol, and sugars. Based on the effects of toxicity and osmotic changes (e.g., salt concentrations) to biological cells, methods to add cryoprotectants are often evaluated in different ways at different temperatures. Mixed samples will be provided a specific time to interact with the cells before cooling ("equilibration time").

\section{Sample packaging, sealing, and labelling}

The choice of packaging containers for samples must be informed by consideration of several factors including efficient heat transfer, manual or automated processing, sealing and labelling, and efficient organization for long-term storage. Containers that have been used for germplasm cryopreservation include plastic straws $(0.25-\mathrm{mL}, 0.5-\mathrm{mL}$, $5-\mathrm{mL})$, glass ampoule tubes, cryovials, and cryobags. Automated processing systems exist for plastic ("French") straws that are used around the world for livestock.

\section{Cooling of samples}

Cooling rate is a critical factor for cell survival and usually needs to be determined experimentally. Cooling can be achieved by use of computer-programmable freezers, liquid 
nitrogen vapors, solid $\mathrm{CO}_{2}$ (dry ice), or other methods, as long as controllable cooling rates can be achieved.

\section{Sample storage in liquid nitrogen}

Storage of samples is commonly performed within liquid nitrogen $\left(-196^{\circ} \mathrm{C}\right)$ or nitrogen vapor $\left(-140^{\circ} \mathrm{C}\right.$ and $\left.180^{\circ} \mathrm{C}\right)$ in specially designed storage dewars (vacuum flasks used for storing cryogens). Theoretically, frozen samples could be stored at these temperatures forever. One report showed that human cryopreserved spermatozoa could be revived after 40 years of storage (Szell et al. 2013).

\section{Thawing for use}

As with the cooling process, warming of frozen samples is critical for survival. Ideally, fast warming rates are preferred as the 2-factor hypothesis described above would predict. The warming process can usually be achieved in a water bath at $40^{\circ} \mathrm{C}-60^{\circ} \mathrm{C}$. Some research has also addressed the use of microwave (Ewert 1988) and infrared laser pulses (Jin and Mazur 2015; Daly et al. 2018). Samples are typically used immediately for fertilization after thawing.

Development of effective, robust, and standardized cryopreservation protocols (as stated above) is essential to assure cell survival, and constitutes the core pathway for application of cryopreservation technology (Tiersch 2011b). In addition to a robust cryopreservation pathway, procedures are required to assure proper germplasm acquisition (including genetic background, sample numbers, and quality), to utilize samples after thawing, and to manage product quality (Hu et al. 2013; Hu et al. 2014). Furthermore, approaches such as databases, sample inventory, daily maintenance to assure liquid nitrogen level, and marketing must be developed for management of germplasm repositories for long-term or commercialized use (Torres and Tiersch 2018).

\section{Application of Germplasm Cryopreservation Technology}

In the United States, male infertility occurs at a 7\% rate, and reproductive-care physicians treat approximately 1.2 million people every year (Kasturi et al. 2008). Sperm cryopreservation has become a standardized approach for clinical treatment of male infertility, and the American Society for Reproductive Medicine has developed sperm banking practices as providers for reproductive treatment to enable them to collect, cryopreserve, and store donor samples. Based on a 1994 survey, 451 sperm banks were available in the United States (Critser 1998), and it has been assumed that more sperm banks have been developed to continue to meet medical treatment needs. In addition, oocyte and embryo vitrification technologies have been applied in infertility treatments as a complement to in vitro fertilization (IVF), and it has been shown that pregnancy rates with frozen oocytes and embryos are comparable with those achieved in fresh cycles (Herrero et al. 2011).

For livestock, sperm cryopreservation technology can provide many advantages, such as efficient use of sperm, storage of sperm in perpetuity, ease of transport, choice of desired sires, and international trade of germplasm resources. With the development of artificial insemination techniques, the American Society of Animal Production (ASAP) was founded in 1939 and promoted the development of cryopreservation technology for sperm sample collection, evaluation, and preservation from domestic animals (Foote 2002). To date, sperm cryopreservation provides multibillion dollar international trade and plays a significant role in the cattle industry (Moore and Hasler 2017). Certified Semen Services (www.naab-css.org/aboutcss), a subsidiary of the National Association of Animal Breeders, provides minimum requirements and management guidelines for this industry. The USDA National Animal Germplasm Program (NAGP) was established in 1999 in Ft. Collins, Colorado, and is the premier animal germplasm repository in the world (https://nrrc.ars.usda. gov/A-GRIN/main_webpage_dev/ars?record_source=US). The NAGP integrates a powerful database with its collections, called the Animal Germplasm Resources Information Network, or Animal GRIN.

For aquaculture fish and shellfish, germplasm cryopreservation technology has been examined in many species (Tiersch et al. 2007; Yang 2017). For fishes, germplasm cryopreservation work has mostly addressed sperm, and to a lesser extent oocytes and embryos. For shellfish, germplasm cryopreservation has been investigated in sperm, oocytes, embryos, and larvae (Yang 2017; Simon and Yang 2018). It is evident that germplasm cryopreservation has a promising future application in breeding, conservation, establishment of self-fertilization lines (Yang et al. 2015), and commercial hybridization (Hu et al. 2011). One of the leading germplasm repositories in the world for fishes is housed at the Zebrafish International Resource Center at the University of Oregon in Eugene (https://zebrafish.org/ home/guide.php). This repository is also linked to a powerful database (http://zfin.org/).

For endangered species conservation, germplasm cryopreservation has much potential (Liu et al. 2019). Biobanking efforts have been made in male fertility preservation 
for rare and endangered species (Comizzoli 2015). For mammals, cryopreservation of ovarian tissues (germ cells) of wild cats is also becoming an important tool for preservation of genetic diversity (Santos et al. 2010), and spermatozoa and oocytes of lions, tigers, and other cat species have been cryopreserved and revived. For endangered fishes, sperm cryopreservation (Tiersch et al. 1998) and germline cryopreservation (Kobayashi et al. 2007) have been applied, and cryopreservation of whole testes of fish has proved to be an effective approach to generate functional sperm and oocytes (Lee et al. 2013).

Overall, germplasm cryopreservation is a useful technology for many promising applications, including clinical treatment, agricultural production, conservation of imperiled species, and biodiversity maintenance. Additionally, this technology also has great application in other organisms such as plants, bacteria, and fungi for long-term preservation and maintenance of biodiversity. This technology is expected to become more available in the future as inexpensive custom-designed devices are developed by use of emerging technologies for computer-assisted design and manufacturing, such as 3-dimensional printing (Tiersch and Monroe 2016).

\section{Acknowledgements}

This review was supported by funds from the Gulf States Marine Fisheries Commission (No. ACQ-210-039-2019USM - Gulf of Mexico Oyster Genetics and Breeding Research Consortium Project) and the National Institute of Food and Agriculture, United States Department of Agriculture (Hatch project FLA-FOR-005385 for Dr. Yang and LAB94231 for Dr. Tiersch). Also, this study was partly supported by the Gulf States Marine Fisheries Commission (ACQ-210-039-2017-UFL2, ACQ- ACQ-210-039-2018UFL), a National Sea Grant Aquaculture Initiative Award (NA18OAR4170344). Support was also provided by the National Institutes of Health, Office of Research Infrastructure Programs (R24-OD010441 and R24-OD011120) and the Louisiana State University Research \& Technology Foundation (AG-2018-LIFT-003).

\section{References}

Anchordoguy, T., J. H. Crowe, F. J. Griffin, and W. H. Clark, Jr. 1988. "Cryopreservation of sperm from the marine shrimp Sicyonia ingentis." Cryobiology 25: 238-43.

Barker, C. A., and J. C. Gandier. 1957. "Pregnancy in a mare resulting from frozen epididymal spermatozoa." Canadian Journal of Comparative Medicine and Veterinary Science 21: 47-51.
Blaxter, J. H. S. 1953. "Sperm storage and cross-fertilization of spring and autumn spawning herring." Nature 172: 1189-90.

Bratton, R. W., R. H. Foote, and J. C. Cruthers. 1955. "Preliminary fertility results with frozen bovine spermatozoa." Journal of Dairy Science 38: 40-6.

Bunge, R. G., and J. K. Sherman. 1953. "Fertilizing capacity of frozen human spermatozoa.” Nature 172: 767-8.

Chen, C. 1986. "Pregnancy after human oocyte cryopreservation." Lancet 1: 884-6.

Comizzoli, P. 2015. "Biobanking efforts and new advances in male fertility preservation for rare and endangered species." Asian Journal of Andrology 17: 640-5.

Corteel, J. M., and G. Baril. 1974. "Viabilite des spermatozoides de bouc cibserves et congeles avec ou sans leur plasma seminal: Effet du glucose." Annales de Biologie Animale, Biochimie, Biophysique 14: 741-5.

Costanzo, J. P., R. E. Lee, and M. F. Wright. 1991. “Glucose loading prevents freezing-injury in rapidly cooled wood frogs." American Journal of Physiology 261: R1549-53.

Critser, J. K. 1998. "Current status of semen banking in the USA.” Human Reproduction 13: 55-67.

Cuevas-Uribe, R., S. P. Leibo, J. Daly, and T. R. Tiersch. 2011. "Production of channel catfish with sperm cryopreserved by rapid non-equilibrium cooling." Cryobiology 63: 186-97.

Daly, J., N. Zuchowicz, C. I. Nuñez Lendo, K. Khosla, C. Lager, E. M. Henley, J. Bischof, F. W. Kleinhans, C. Lin, E. C. Peters, and M. Hagedorn. 2018. "Successful cryopreservation of coral larvae using vitrification and laser warming." Scientific Reports 8: 15714.

Davenport, C. B. 1897. Experimental Morphology. Part 1: Effect of Chemical and Physical Agents upon Protoplasm. Macmillan, New York; London.

Dueck, C. E. 2018. "Cryogenic hibernation: A review of overwintering mechanisms in the north American wood frog (Rana sylvatica)." Proceedings of Manitoba's Undergraduate Science and Engineering Research 4: 72-73. 
Ewert, L. 1988. "Experiments on preparation of boar spermatozoa for cryoconservation in straws and biologicalphysical aspects of thawing by microwaves." p. 91. University of Veterinary Medicine Hannover, Hannover, Germany.

Foote, R. H. 2002. "The history of artificial insemination: Selected notes and notables." Journal of Animal Science 80: $1-10$.

Fuller, B., N. Lane, and E. Benson. 2004. Life in the Frozen State. CRC Press, New York.

Hammond, J. 1930. "The effect of temperature on the survival In Vitro of rabbit spermatozoa obtained from the vagina." Journal of Experimental Biology 7: 175-95.

Harvey, B., R. N. Kelley, and M. J. Ashwood-Smith. 1982. "Cryopreservation of zebrafish spermatozoa using methanol." Canadian Journal of Zoology 60: 1867-70.

Herrero, L., M. Martinez, and J. A. Garcia-Velasco. 2011. "Current status of human oocyte and embryo cryopreservation." Current Opinion in Obstetrics and Gynecology 23: $245-50$.

Hoagland, H., and G. Pincus. 1942. "Revival of mammalian sperm after immersion in liquid nitrogen " The Journal of General Physiology 25: 337-44.

Hu, E., B. Bosworth, J. Baxter, and T. Tiersch. 2014. "Onsite evaluation of commercial-scale hybrid catfish production using cryopreserved blue catfish sperm." Aquaculture 426-427: 88-95.

Hu, E., T. W. Liao, and T. R. Tiersch. 2013. "A quality assurance initiative for commercial-scale production in high-throughput cryopreservation of blue catfish sperm." Cryobiology 67: 214-24.

Hu, E., H. Yang, and T. R. Tiersch. 2011. "High-throughput cryopreservation of spermatozoa of blue catfish Ictalurus furcatus: Establishment of an approach for commercialscale processing." Cryobiology 62: 74-82.

Jahnel, F. 1938. “Über die widerstandsfähigkeit von menschlichen spermatozoen gegennumber starker k/:lte." Klinische Wochenschrift 17: 1273-4.

Jin, B., and P. Mazur. 2015. "High survival of mouse oocytes/embryos after vitrification without permeating cryoprotectants followed by ultra-rapid warming with an IR laser pulse." Scientific Reports 5: 9271.
Kasturi, S. S., J. Tannir, and R. E. Brannigan. 2008. “The metabolic syndrome and male infertility." Journal of Andrology 29: 251-9.

Kobayashi, T., Y. Takeuchi, T. Takeuchi, and G. Yoshizaki. 2007. "Generation of viable fish from cryopreserved primordial germ cells." Molecular Reproduction and Development: Incorporating Gamete Research 74: 207-13.

Kuwayama, M., G. Vajta, O. Kato, and S. P. Leibo. 2005. "Highly efficient vitrification method for cryopreservation of human oocytes." Reproductive BioMedicine Online 11: $300-8$.

Lannan, J. E. 1971. "Experimental self-fertilization of Pacific oysters, Crassostrea gigas, utilizing cryopreserved sperm." Genetics 68: 599-601.

Lee, S., Y. Iwasaki, S. Shikina, and G. Yoshizaki. 2013. "Generation of functional eggs and sperm from cryopreserved whole testes." Proceedings of the National Academy of Sciences 110: 1640-5.

Leibo, S. P. 1976. Preservation of mammalian cells and embryos by freezing. Oak Ridge National Laboratory, Tennessee, US.

Liu, Y., H. Blackburn, S. S. Taylor, and T. R. Tiersch. 2019. "Development of germplasm repositories to assist conservation of endangered fishes: Examples from small-bodied livebearing fishes." Theriogenology 135: 138-51.

Lovelock, J. E. 1953a. "The haemolysis of human red blood cells by freezing and thawing." Biochimica Et Biophysica Acta 10: 414-26.

Lovelock, J. E. 1953b. "Het mechanism of the protective action of glycerol against haemolysis by freezing and thawing." Biochimica Et Biophysica Acta 11:28-36.

Lovelock, J. E. 1954. "The protective action of neutral solutes against haemolysis by freezing and thawing." Biochemical Journal 56: 265-70.

Lovelock, J. E., and M. W. H. Bishop. 1959. "Prevention of freezing damage to living cells by dimethyl sulphoxide." Nature 183: 1394-5.

Luyet, B. J., and E. L. Hodapp. 1938. "Revival of frog's spermatozoa vitrified in liquid air." Proceedings of the Society for Experimental Biology and Medicine 39: 433-4. 
Mazur, P. 1963. "Kinetics of water loss from cells at subzero temperature and the likelihood of intracelluar freezing." The Journal of General Physiology 47: 347-69.

Mazur, P. 1965. "The role of cell membranes in the freezing of yeast and other single cells." Annals of the New York Academy of Sciences 125: 658-76.

Mazur, P. 1970. "Cryobiology: The freezing of biological systems.” Science 168: 939-49.

Mazur, P., S. P. Leibo, and E. H. Y. Chu. 1972. "2-factor hypothesis of freezing injury-evidence from Chinese hamster tissue culture cells." Experimental Cell Research 71: 345-255.

Moore, S. G., and J. F. Hasler. 2017. "A 100-year review: Reproductive technologies in dairy science." Journal of Dairy Science 100: 10314-31.

Morozov, V. A. 1940. "The application of low temperatures for storage of bull sperm." Vestnik sel'sko-khozyaistvennoi Nauki, Moskva. Zhivotnov 139-47.

Paniagua-Chavez, C. G., J. T. Buchanan, J. E. Supan, and T. R. Tiersch. 1998. "Settlement and growth of Eastern oysters produced from cryopreserved larvae.” Cryoletters 19: 28392.

Parkening, T. A., and M. C. Chang. 1976. "In-vitro fertilization of ova from senescent mice and hamsters." Journal of Reproduction and Fertilility 48: 381-3.

Parkes, A. S. 1945. "Preservation of human spermatozoa at low temperatures." British Medical Journal 2: 212-3.

Pegg, D. E. 2002. “The history and principles of cryopreservation." Seminars in Reproductive Medicine 20: 5-13.

Platz, C. C., D. E. Wildt, and S. W. J. Seager. 1978. "Pregnancy in the domestic cat after artificial insemination with previously frozen spermatozoa." Reproduction 52: 279-82.

Polge, C., and L. E. A. Rowson. 1952. "Fertilizing Capacity of Bull Spermatozoa after Freezing at -79 Degrees C.” Nature 169: 626-7.

Polge, C., A. U. Smith, and A. S. Parkes. 1949. "Revival of spermatozoa after vitrification and dehydration at low temperatures." Nature 164: 666.
Pursel, V. G., and L. A. Johnson. 1975. "Freezing of boar spermatozoa: Fertilizing capacity with concentrated semen and a new thawing procedure." Journal of Animal Science 40: 99-102.

Rall, W. F., and G. M. Fahy. 1985. "Ice-free cryopreservation of mouse embryos at -196-degree-C by vitrification."

Nature 313: 573-5.

Rostand, J. 1946. "Glycérine et résistance du sperme aux basses températures." Comptes rendus de l'Académie des Sciences 222: 1524-5.

Santos, R. R., C. Amorim, S. Cecconi, M. Fassbender, M. Imhof, J. Lornage, M. Paris, V. Schoenfeldt, and B. Martinez-Madrid. 2010. "Cryopreservation of ovarian tissue: An emerging technology for female germline preservation of endangered species and breeds." Animal Reproduction Science 122: 151-63.

Seager, S. W. J. 1969. "Successful pregnancies utilizing frozen dog semen.” Artificial Intelligence Digest 17: 6-16.

Shaffner, C. S. 1942. "Longevity of flow spermatozoa in frozen condition " Science 96: 337.

Shaffner, C. S., E. W. Henderson, and C. G. Card. 1941. "Viability of spermatozoa of the chicken under various environmental conditions." Poultry Science 20: 259-65.

Sherman, J. K. 1973. "Synopsis of the use of frozen human semen since 1964: State of the art of human semen banking." Fertility and Sterility 24: 397-412.

Shettles, L. B. 1939. "The respriation of human spermatozoa and their response to various gases and low temperature." American Journal of Physiology-Legacy Content 128: 408-15.

Simon, N. A., and H. Yang. 2018. "Cryopreservation of trochophore larvae from the hard clam Mercenaria mercenaria: Evaluation of the cryoprotectant toxicity, cooling rate and thawing temperature." Aquaculture Research 49: 2869-80.

Smith, A. U., C. Polge, and J. Smiles. 1951. "Microscopic observation of living cells during freezing and thawing." Journal of the Royal Microscopical Society 71: 186-95.

Szell, A. Z., R. C. Bierbaum, W. B. Hazelrigg, and R. J. Chetkowski. 2013. "Live births from frozen human semen stored for 40 years." Journal of Assisted Reproduction and Genetics 30: 743-4. 
Tada, N., M. Sato, J. Yamanoi, T. Mizorogi, K. Kasai, and S. Ogawa. 1990. "Cryopreservation of mouse spermatozoa in the presence of raffinose and glycerol." Journal of Reproduction and Fertility 89: 511-6.

Tiersch, T. R. 2011a. "Introduction to the second edition." In: Cryopresevation in Aquatic Species," edited by T. R. Tiersch and C. C. Green, pp. 134-44. World Aquaculture Society, Baton Rouge.

Tiersch, T. R. 2011b. "Process pathways for cryopreservation research, application and commercialization." In: Cryopreservation in Aquatic Species, edited by T. R. Tiersch and C. C. Green, pp. 646-71. World Aquaculture Society, Baton Rouge, LA.

Tiersch, T. R., C. R. Figiel Jr, W. R. Wayman, J. H. Williamson, G. J. Carmichael, and O. T. Gorman. 1998. "Cryopreservation of sperm of the endangered razorback sucker." Transactions of the American Fisheries Society 127: 95-104.

Tiersch, T. R., and W. T. Monroe. 2016. “Three-dimensional printing with polylactic acid (PLA) thermoplastic offers new opportunities for cryobiology." Cryobiology 73: 396-8.

Tiersch, T. R., H. Yang, J. A. Jenkins, and Q. Dong. 2007. "Sperm cryopreservation in fish and shellfish." In: Spermatology (Soc Reprod Fertil Supplement 65), edited by R. E.R.S. and M. Gomendio, pp. 493-508. Nottingham University Press, Nottingham.

Torres, L., Y. Liu, A. Guitreau, H. Yang, and T. R. Tiersch. 2017. "Challenges in development of sperm repositories for biomedical fishes: Quality control in small-bodied species." Zebrafish 14: 552-60.

Torres, L., and T. R. Tiersch. 2018. "Addressing reproducibility in cryopreservation, and considerations necessary for commercialization and community development in support of genetic resources of aquatic species." Journal of the World Aquaculture Society 49: 644-63.

Walters, E. M., J. D. Benson, E. J. Woods, and J. K. Critser. 2009. “The history of sperm cryopreservation." In: Sperm Banking: Theory and Practice, edited by A. A. Pacey and M. J. Tomlinson. 1-17. Cambridge University Press.

Watson, P. F., and I. C. Martin. 1973. "The response of ram spermatozoa to preparations of egg yolk in semen diluents during storage at 5 or -196 degrees C." Australian Journal of Biological Sciences 26: 927-35.
Whittingham, D. G., S. P. Leibo, and P. Mazur. 1972. "Survival of mouse embryos frozen to $-196^{\circ}$ and $-269^{\circ} \mathrm{C}$." Science 178: 411-4.

Wilmut, I., and L. E. Rowson. 1973. "Experiments on the low-temperature preservation of cow embryos." Veterinary Record 92: 686-90.

Yang, H. 2017. "Application of germplasm preservation in breeding programs for molluscan shellfish aquaculture and restoration." Bulletin of Japan Fisheries Research and Education Agency 45: 15-20.

Yang, H., L. Hazlewood, S. J. Heater, P. A. Guerrero, R. B. Walter, and T. R. Tiersch. 2007. "Production of F1 interspecies hybrid offspring with cryopreserved sperm from a live-bearing fish, the swordtail Xiphophorus helleri." Biology of Reproduction 76: 401-6.

Yang, H., Y. Wang, X. M. Guo, and T. R. Tiersch. 2015. "Production of inbred larvae through self-fertilization using oocytes and cryopreserved sperm from the same individuals after sex reversal in eastern oyster Crassostrea virginica." Aquaculture Research 46: 2153-65. 
Table 1. Examples of milestone achievements in cryopreservation of animal cells and tissues.

\begin{tabular}{|c|c|c|c|}
\hline Year & First Author & Organism & Findings \\
\hline 1949 & Polge & human, bull, fowl & Glycerol found to protect sperm during cryopreservation \\
\hline 1952 & Polge & bull & Production of the first calf from thawed spermatozoa \\
\hline 1953 & Bunge & human & Fertility capacity of thawed spermatozoa \\
\hline 1953 & Blaxter & herring & First report of sperm cryopreservation in a bony fish \\
\hline 1955 & Bratton & bull & Production of offspring from thawed sperm after 103 -day storage at $-79^{\circ} \mathrm{C}$ \\
\hline 1957 & Barker & horse & First report of pregnancy from thawed epididymal spermatozoa \\
\hline 1959 & Lovelock & human, bovine & Dimethyl sulfoxide (DMSO) found as cryoprotectant for red blood cells \\
\hline 1969 & Seager & $\operatorname{dog}$ & Production of first birth from thawed spermatozoa \\
\hline 1971 & Lannan & Pacific oysters & First report of sperm cryopreservation in molluscan shellfish \\
\hline 1972 & Mazur & hamster cell line & Proposal of 2-factor hypothesis of cell injury during cooling and warming \\
\hline 1972 & Whittingham & mouse & Newborn production from thawed embryo after 8-day storage at $-196^{\circ} \mathrm{C}$ \\
\hline 1973 & Watson & ram and bull & Discovery of lipid (egg yolk) protection on sperm during cooling \\
\hline 1973 & Wilmut & cow & Newborn produced from thawed embryos \\
\hline 1974 & Corteel & goat & Cryopreservation effect of washing spermatozoa before cooling \\
\hline 1975 & Pursel & boar & Pregnancy and fertilization by thawed semen comparable to fresh semen \\
\hline 1976 & Parkening & mouse & Survival, fertility, and development of thawed mouse oocytes \\
\hline 1978 & Platz & domestic cat & First report of newborn from thawed spermatozoa \\
\hline 1982 & Harvey & zebrafish & First report on sperm cryopreservation and fertility after thawing \\
\hline 1985 & Rall & mouse & Ice-free fast cooling of embryos at $-196^{\circ} \mathrm{C}$ (vitrification) \\
\hline 1986 & Chen & human & First report of pregnancy from thawed oocytes \\
\hline 1988 & Anchordoguy & shrimp & First report of sperm cryopreservation (without fertility testing) \\
\hline 1990 & Tada & mouse & First successful sperm cryopreservation \\
\hline 1998 & Paniagua & eastern oyster & First production of offspring from cryopreserved oyster larvae \\
\hline 2005 & Kuwayama & human & First fast-freezing method of oocytes, and newborn production \\
\hline 2007 & Yang & Xiphophorus helleri & First offspring production from thawed spermatozoa in live-bearing fishes \\
\hline 2011 & Cuevas-Uribe & channel catfish & First catfish production from cryopreserved sperm by vitrification \\
\hline 2018 & Daly & coral Fungia scutaria & First coral larvae survival from vitrification \\
\hline \multicolumn{4}{|c|}{$\begin{array}{l}\text { (Polge et al. 1949; Polge and Rowson 1952; Blaxter 1953; Bunge and Sherman 1953; Bratton et al. 1955; Barker and Gandier 1957; Lovelock } \\
\text { and Bishop 1959; Seager 1969; Lannan 1971; Mazur et al. 1972; Whittingham et al. 1972; Watson and Martin 1973; Wilmut and Rowson 1973; } \\
\text { Corteel and Baril 1974; Pursel and Johnson 1975; Parkening and Chang 1976; Platz et al. 1978; Harvey et al. 1982; Rall and Fahy 1985; Chen } \\
\text { 1986; Anchordoguy et al. 1988; Tada et al. 1990; Paniagua-Chavez et al. 1998; Kuwayama et al. 2005; Yang et al. 2007; Cuevas-Uribe et al. 2011; } \\
\text { Daly et al. 2018) }\end{array}$} \\
\hline
\end{tabular}

